\title{
Artificial Intelligence Modules for Higher Educational Institutions
}

\author{
Delali Kwasi Dake \\ Department of ICT Education \\ University of Education, Winneba Ghana
}

\author{
Ahmed Halil \\ Department of ICT Education \\ University of Education, Winneba Ghana
}

\begin{abstract}
5G network has been a major research discussion and its emergence has led to a higher interest in Internet of Things, Tactile Internet and Big Data. These explosive technologies has led to an era of Data Science where intelligence gathering concepts in applications are becoming important. The purpose for this research is to examine how Artificial Intelligence technologies can be deployed in higher educational institutions in facilitating the work of students, administrators and academic authorities in the sector. The paper considers four major areas in Tertiary Education whose operations can be enhanced with Artificial Intelligence. These include; Students Admission, the Library, Student Personal Learning Guide and the Classroom. The paper proposes modules that seeks to depict Artificial Intelligence integration for a Smart Campus.
\end{abstract}

\section{Keywords}

5G Networks, Artificial Intelligence, Data Mining, Machine Learning, Internet of Things.

\section{INTRODUCTION}

Machines are becoming more sophisticated daily [1]. As technology advances, modern machines go beyond automation of tasks to the extent of exhibiting intelligence in their operations. The emergence of $5 \mathrm{G}$ with higher speed and low latency will serve as a backbone that will increase the number of connected devices, Internet of Things (IoT) and the intelligence monitoring in Big Data [2]. Artificial Intelligence (AI) integration will provide opportunity for systems to automatically learn and take decisions on their own.

AI powered technologies are visible today. Smart Digital Assistants, Tesla, Virtual Assistants, Google Assistant, Alexa and Siri are applications that exhibit intelligence in their operations. AI is applied widely in industry and shaping the industrial sector at a fast pace. It has become a significant part of industries that automate their processes [3].

In the area of Education, new learning methods are introduced to students with instructors embracing the constructivist-based pedagogy [4] where the learner can learn from experience. Learning Management Systems (LMS) [5] are widely adopted by Educational Institutions for tracking, reporting and delivery of educational courses.

Blended Learning Applications [6] are also at the forefront of Education since most Tertiary Institutions now have distance learning modules in their curriculum. This paper focuses on the integration of A.I modules in Education in deriving some intelligence especially for pattern predictions and personalized learning. The areas of focus for this paper are the admissions, the library, the classroom and how AI can enhance students' personal out-of-class learning activities.

\section{REVIEW OF LITERATURE}

Artificial intelligence as a branch of science aims at creating intelligent machines that can think and act like humans. [7] states that the purpose of Artificial Intelligence is to try to mimic human consciousness and perform tasks such as human beings. In practice it means the ability of a machine or program to think and learn. Skouby and Lynggaard [8] proposed an Advanced ICT based infrastructure for future smart home. In the infrastructure as shown in Fig. 1, the smart home is equipped with Advanced Artificial Intelligent (AAI) systems which controls and processes its smart home services. The household objects such as toothbrush, clothes, television, etc. will have some IoT technology integration that will aid the AAI systems for an efficient smart home.

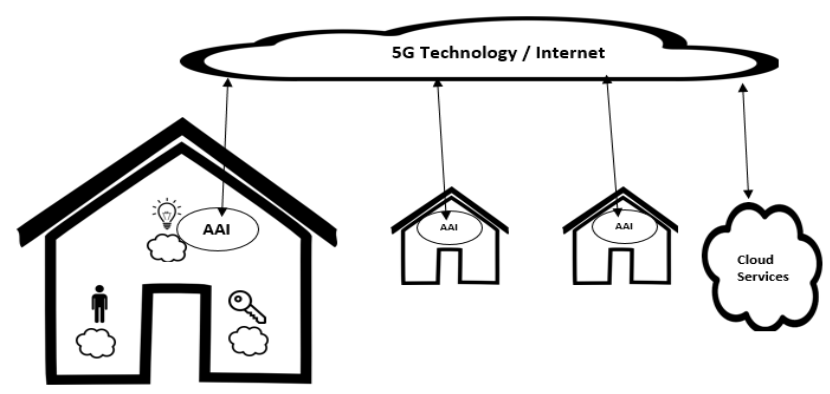

Fig. 1: Advanced ICT based infrastructure for future smart home ([8])

Estisilat-BT Innovation Center [EBTIC] [9], created a holistic next-generation intelligent campus framework, iCampus for $21^{\text {st }}$ century campus environment. The iCampus framework as shown in Fig. 2, consist of iLearning, iSocial, iGreen, iHealth, iManagement and iGovernance aspect of campus. The proposed framework can work independently and interdependently to integrate campus with interactivity and intelligence gathering.

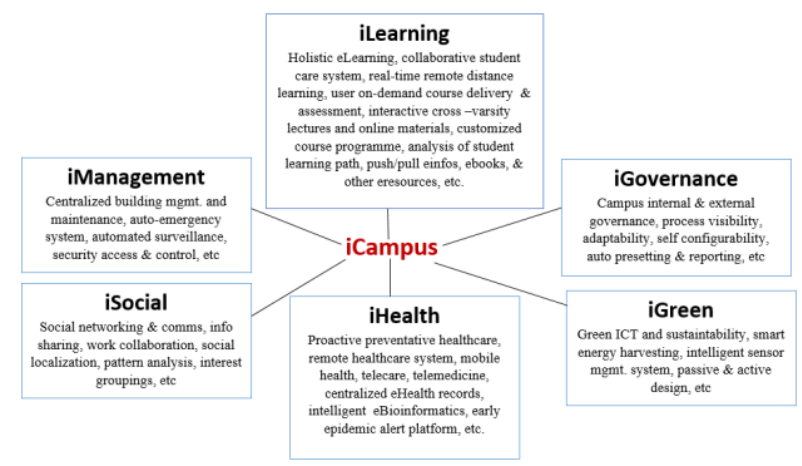

Fig. 2: Pillars of Intelligent Campus Framework ([9]) 
Aguilar, Valdiviezo, Schooler, Cordero, \& Sánchez [10] proposed a conceptual design of a smart classroom based on multi-agent paradigm, called SaCI. Two agents were proposed, one to characterize the software components and the other to define the hardware components. The SaCI framework adopted a middleware [11] for multi-agent systems and agent for conversation using MASINA [12].

The AARTIC Project [13] proposes an intelligent system for assisting software engineering students in their assignments. Two agents were proposed: one for student activity supervision and the other to allow the teacher in evaluating the class and each learner. The agent activities were based in Machine Learning techniques.

\section{ARTIFICIAL INTELLIGENCE MODULES FOR SMART CAMPUS}

\subsection{Artificial Intelligence in Admission -} Smart Admission.

The Artificial Intelligence Powered Centralized Application (AIPCA) platform describes a single admission or application platform that connects tertiary institutions to prospective students or applicants. The platform operates with the possibility of an applicant applying to more than one school with an application voucher. The system also predicts to an applicant the probability of getting admitted into a particular institution.

The centralized application platform relies on the data it gathers from school websites, search engines and user survey data to make decisions and predictions.

Fig. 3 presents a module that represents the integration of Artificial Intelligence in smart admission.

\section{Key Terms to illustrate the operations of AIPCA}

Applicant: Applicant here refers to the user who wants to apply for admission.

School: This refers to the various universities and the courses they offer.

SE: This refers to search engines.

SC: This refers to school websites.

Knowledge Base: This is at the center of the AI Centralized Admission System. The Knowledge base is integrated with Machine Learning (ML) algorithms to analyze the Big Data after sorting and matching.

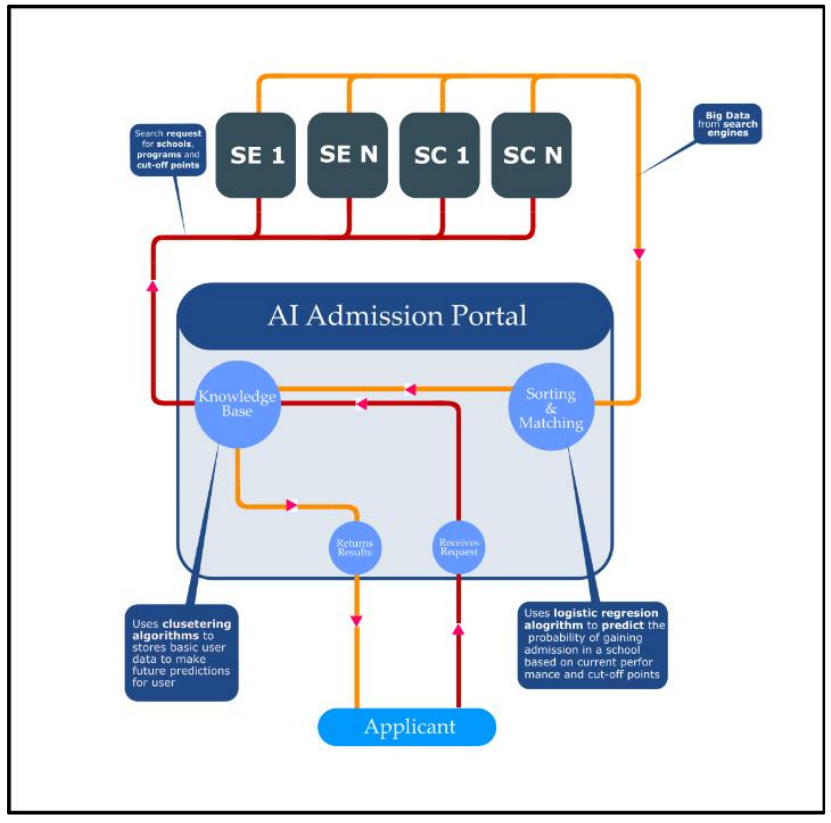

Fig. 3: AI Centralized Application System - AIPCA

\section{Operating Mechanisms of AIPCA}

Applicant buys an application voucher.

Applicant creates an account with the portal and submits examination grades.

The applicant also has an option to select a course and the school of choice.

The AIPCA scans through search engines and return schools in the country that offer programs or courses related to the applicant's choice with their admission requirements.

Through an efficient sorting algorithm, the AIPCA selects from the search results the most appropriate courses that match the performance of the user in terms of grades.

The sorting helps to get the list of schools that offer such programs as the applicant want, compare the general program requirements in each school to see if user qualifies and predicts the likelihood of an applicant gaining admission in the school.

The course requirements and user grades is then compared with current trends in school applications. This data is stored in the Knowledge Base of the Application Portal. A performance comparison is then made of the user and other applicants based on similar course and school. Machine Learning (ML) algorithms are then deployed to predict the probability of the applicant gaining admission into a particular program in a school.

The last stage is to return the results to the user. The results include the schools that offer the users program of choice or suggested programs and the probability of gaining admission. 


\subsection{Artificial Intelligent Library Assistant - Smart Library.}

The Artificial Intelligent Library Assistant (AILA) is an interactive robot situated in the library and available on the mobile devices of library users as a virtual assistant. Like a human assistant in the library, AILA can attend to the information needs of the library user. A user walks to the AILA to ask questions for answers and also makes searches for books, publications and other information that is available not just within the library but on other connected libraries in the cloud.

The module as shown in Fig 4 explains how an Artificially Intelligent Library Assistant can add to the features of a smart campus. It describes the interaction between users and the AILA.

\section{Key Terms to illustrate the operations of AILA}

Library user: This refers to the leaner who searches for information in the library. They could be present in the library to interact with the robotic library assistant or access it form their mobile devices.

User Preferences: These refers to user search patterns and preferences. The AILA learns more about the user when user interacts with the system. It is only when the AILA knows that user's preferences that it can sort information to suite the user.

Connected libraries: This refers other online, open libraries that are connect to the cloud.

Forums, Journals, SE: This refers to online forums, journals and search engines.

Electronic Catalogue: These are the library's electronic collection of books and resources.

Offline Catalogue: These are the hard copy books that are kept on the shelves in the library.

Knowledge Base (KB): Knowledge Base is the brain of the Artificial Intelligent Library Assistant. This is where training set data of previous activities is stored.

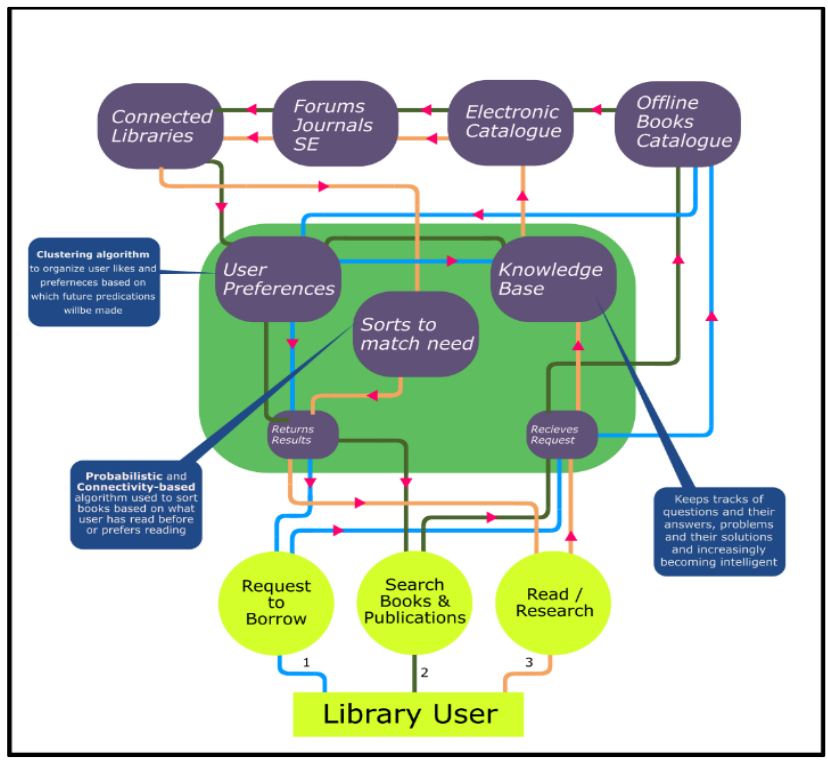

Fig. 4: AI Library Assistant - AILA
Operating Mechanisms of AILA

In the library, AILA takes the form of a Robotic Assistant (RA) that can be positioned as a front desk assistant. The library user walks to the AILA and makes any of the following requests. These requests can be grouped into events as follows:

a. Event 1: Make a request to borrow a book and other materials.

b. Event 2: Search for books, journals and publications.

c. Event 3: Conduct mini searches for information.

Event 1: The AILA after receiving request for a book scans through the library's electronic catalogue of resources to find out if the requested book is available for the user or has been borrowed already.

If the book is available, with the help of connected shelves, the AILA determines the shelves on which the said material is located, and directs the user to that particular shelve. AILA then stores this data in the user preferences.

If the book is not available or has been borrowed, it tells the user when the book was taken and when it will be available. It also asks if the user wants to be notified as soon as the book is return back to the shelves.

Event 2: When a library user makes a search request for books and publications, AILA first scans through the library's offline resources catalogue to find books that match the search of the user. Secondly, the system scans through the electronic catalogue of resources, then to online forums and journals and finally to other connected libraries in the cloud to find matching results to the user's needs. The big data generated from these searches is sent back to the system for sorting. A probabilistic and connectivity-based algorithm is used to sort the book and search results based on user history.

Event 3: When a library user wants to make a research on a particular topic or subject matter, the AILA first searches through its knowledge base and then to the libraries electronic catalogues to find relevant answers to the question. It proceeds to search through other forums, journals sites and search engines online if there no relevant answers. AILA can also search through other libraries connected to the cloud in extreme scenarios.

The results gathered from these searches (Big Data) are then sorted. Sorting is done is order to return the most relevant answer to the user.

\subsection{The Artificial Intelligence Learning Companion - Smart Learning.}

As shown in Fig. 5, the Artificial Intelligence Learning Companion (AILC) is a Virtual Learning Assistant on the mobile device of the user. Its purpose is to assist the student in class learning activities.

\section{Key Terms to illustrate the operations of AILC}

Electronic Libraries: This refers other online, open libraries that are connect to the cloud.

Connected Library: This refers to the Library's electronic catalogue of resource including the AILC.

Performance Tracker: Keeps track of user's performance in drills and stores the results in the Knowledge Base. 
Search Engines (SE): Refers to search engines such as Google, Bing, and DuckDuckGo.

Knowledge Base: Connects directly to SE and Electronic Libraries.

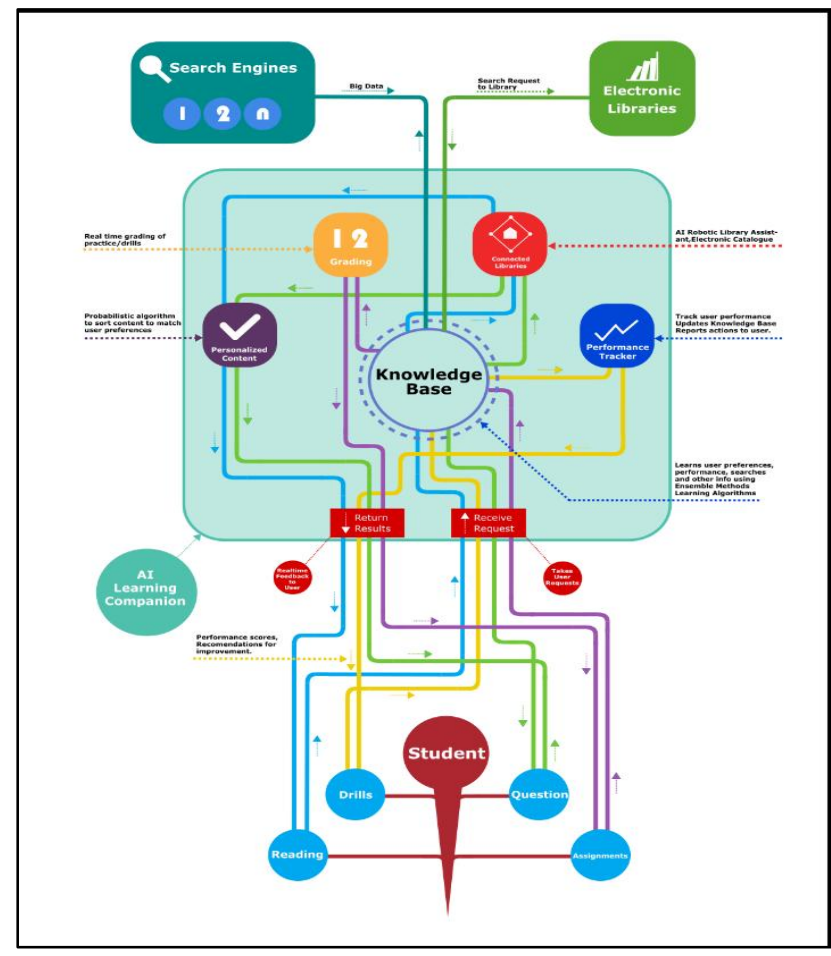

Fig. 5: AI Learning Companion - AILC

Operating Mechanisms of AILC

A student as an external entity who has many needs may want to undertake any of the following:
a. Event 1: Further Reading.
b. Event 2: Practice or Drills.
c. Event 3: Ask a Question.
d. Event 4: Exercise and Assignments.

Event 1: Event one describes a learner's request to read further on a selected topic or subject matter. When the AI Learning Companion receives such request from the user, it first searches (synonym) through its Knowledge Base, where the information it learns is stored to find reading materials that match the request of the user. The AI then searches through the connected library for any new information relating to the subject.

The information gathered from these searches are then personalized to suite the user's preferences in its Knowledge Base. The information is then presented to the user based on the priorities set by the user from the training data.

Event 2: When the user wants to take a drill or exercise, the AI Learning Companion fetches test questions from its Knowledge Base and presents to the user as a test. The Performance Tracker of the AILC keeps track of the learner's performance in tests and provides feedback to the user on ways to improve test performance.

Event 3: When a user asks a question, the AILC first point of reference is the Knowledge Base, where it keeps information. If AILC does not have the answer in the Knowledge Base, further search is done through the library's electronic catalogue of resources and results returned to the user.

Event 4: This event explains an activity or a situation where the learner has to take or submit an assignment given by an Instructor through the AI Learning Companion.

Once the assignment is submitted by the AI Learning Companion, it gets stored in the Knowledge Base where the instructor can access the submitted works. Depending on the grading strategy, which is done by the Instructor or AILC, the grading activity is triggered and the student work is graded with instant feedback to the learner.

\subsection{Artificial Intelligence in Classroom - Smart Classroom}

The Fig. 6 module depicts how Artificial Intelligence in Classroom (AIC) can be adapted for instructional purposes. The AI Classroom system is presented as an independent entity. There is also an interactive blackboard, search engine and the library that are connected to the AIC.

\section{Key Terms to illustrate the operations of AIC}

Knowledge Base: The Knowledge Base is critical to the operations of the system. The system learns and stores user preferences here.

Instructional Content: These are the electronic teaching and learning materials that are added to the system by the instructor or generated by the system.

Performance Tracker: A part of the system that keeps record of student performance and make suggestions for performance improvement.

Real Time Test: These are in-class tests that students can take under the directives of the instructor.

Interactive Blackboard: the interactive blackboard is used to display lesson content

Search Engines: Systems searches are done using the search engines

Connected Libraries: These are online libraries and search engines that are connected to the system.

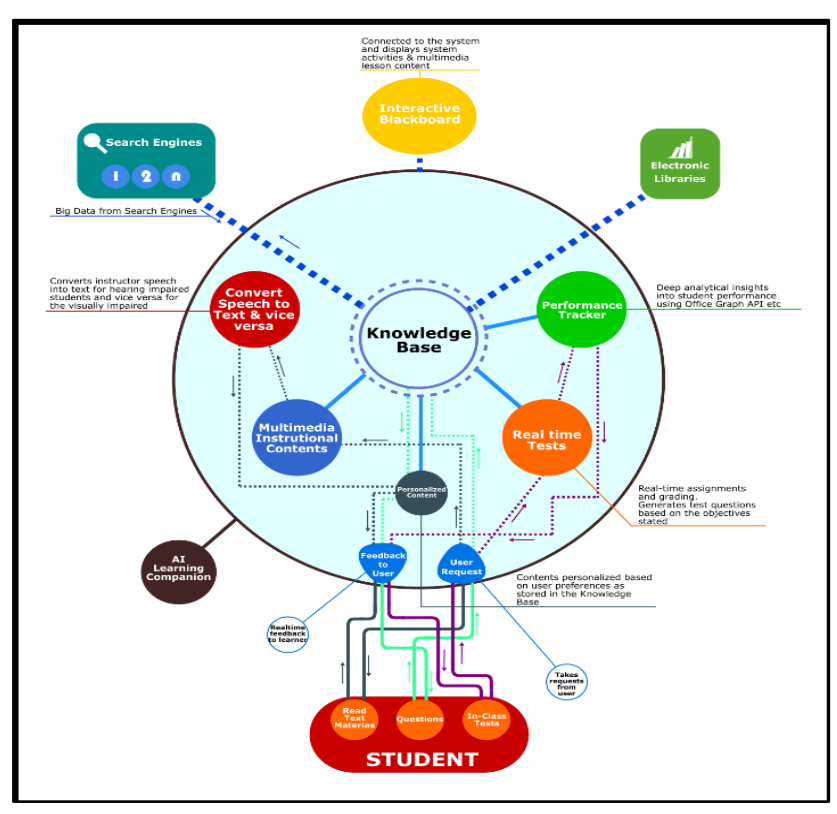

Fig. 6 : AI in Classroom - AIC 


\section{Operating Mechanisms of AIC}

The lecture hall is the primary venue or place where learners receive instruction. In the classroom, learners can read or take lesson notes from the instructor. They can also ask questions about concepts that they are not familiar with. In-class tests or quizzes supervised by the instructor can also be done. These tests are either graded in class or at another time out-of-class. Feedback from these tests are given back to the learner at a later date.

The use of AI in the classroom helps improve classroom practices and activities. With the AIC system, if a learner wants to read a course or lesson material, the system fetches the lesson content. Depending on the learners condition (since it knows the learner), the system will convert the lesson materials to a more appropriate format for use by the learner. If the learner has an impairment, the lesson can be converted appropriately.

Hearing impaired students require a sign language interpreter in an inclusive classroom. With the AI Classroom System, audio based content will be converted into text and graphics for such students. Instructor speech will also be detected and converted into text for reading by peculiar learners. The most appropriate content is then displayed back to the user's screen.

The second activity depicts a scenario where a learner wants to ask a question. The system looks through its Knowledge Base (where it stores learned facts) to find the most appropriate answer to the users question. The $\mathrm{KB}$ is also connected to external libraries and search engines. The gathered answers are then sorted to match the learner's preference.

The last event describes how learners can take in-class tests on AIC. If a test activity is initiated by the instructor, the AI Classroom system will generate test questions from its Knowledge Base. The complexity of these questions will reflect the objectives covered in the lesson as determined by the instructor.

\section{CONCLUSION AND FUTURE WORK}

The emergence of $5 \mathrm{G}$ networks with accompanying IoT and Big Data technologies will need an Artificial Intelligence Integration for predictive and self-learning systems. Smart Campus will become a hub in the near future when these technologies are fully adopted in our tertiary institutions. Learner-centered learning and intelligence gathering for curriculum re-design are important if institutional growth and learner's progress are relevant to authorities.

The modules in this paper will form a blueprint in the integration of A.I with these emerging technologies for Tertiary Institutions. The concepts in the modules are well designed and drawn to depict some selected modules of smart campus. In future research, other areas of smart campus will be implemented as modules.

\section{REFERENCES}

[1] Hoc, J. M. (2000). From human-machine interaction to human-machine cooperation. Ergonomics, 43(7), 833843.
[2] Imran, A., Zoha, A., \& Abu-Dayya, A. (2014). Challenges in 5G: how to empower SON with big data for enabling 5G. IEEE network, 28(6), 27-33.

[3] Skouby, K. E., \& Lynggaard, P. (2014, November). Smart home and smart city solutions enabled by $5 \mathrm{G}$, IoT, AAI and CoT services. In 2014 International Conference on Contemporary Computing and Informatics (IC3I) (pp. 874-878). IEEE.

[4] Jones, M. G., \& Brader-Araje, L. (2002). The impact of constructivism on education: Language, discourse, and meaning. American Communication Journal, 5(3), 1-10.

[5] Weaver, D., Spratt, C., \& Sid Nair, C. (2008). Academic and student use of a learning management system: Implications for quality. Australasian journal of educational technology, 24(1).

[6] Singh, H. (2003). Building effective blended learning programs. Educational Technology-Saddle Brook Then Englewood Cliffs NJ-, 43(6), 51-54.

[7] Pomerol, J. C. (1997). Artificial intelligence and human decision making. European Journal of Operational Research, 99(1), 3-25.

[8] Skouby, K. E., \& Lynggaard, P. (2014, November) Smart home and smart city solutions enabled by $5 \mathrm{G}$, IoT, AAI and CoT services. In 2014 International Conference on Contemporary Computing and Informatics (IC3I) (pp. 874-878). IEEE.

[9] J. Ng, "White paper: The intelligent campus (icampus)," Etisalat BT Innovation Center (EBTIC), Tech. Rep., $2010 . \quad$ [Online]. Available: http://events.kustar.ac.ae/EBTIC/WP/The_Intelligent_ Campus_(iCampus)_V2.pdf

[10] Aguilar, J., Valdiviezo, P., Cordero, J., \& Sánchez, M. (2015). Conceptual design of a smart classroom based on multiagent systems. In Proceedings on the International Conference on Artificial Intelligence (ICAI) (p. 471). The Steering Committee of The World Congress in Computer Science, Computer Engineering and Applied Computing (WorldComp).

[11] M. Sánchez et J. Aguilar, «AmICL Middleware Reflexivo para Ambientes Inteligentes de Aprendizaje en la Nube,» Mérida, Venezuela, June 2014.

[12] J. Aguilar, I. Besembel, M. Cerrada, F. Hidrobo et F. Narciso, «Una metodología para el Modelado de Sistemas de Ingeniería Orientado a Agentes,» Inteligencia Artificial: revista iberoamericana de inteligencia artificial, vol. 12, $\mathrm{n}^{\circ}$ $\% 138$, p. 39-60, 2008.

[13] F. Mhiri et S. Ratté, «AARTIC: development of an intelligent environment for human learning,» chez Proceedings of the 14th annual ACM SIGCSE conference on Innovation and technology in computer science education (ITiCSE '09), Paris, France, July 2009. 